\title{
Case Report: Resolution of Rheumatoid Arthritis in a Patient Consuming Psilocybin Mushrooms
}

\author{
Denise S Lin, MD* \\ Departments of Psychiatry and Behavioral Science, University of New Mexico School of Medicine, Albuquerque, NM, \\ USA
}

A 64 y/o generally healthy and physically active Caucasian male was referred by his PCP for outpatient rheumatology evaluation in March, 2014.

The patient presented to his rheumatology appointment with the complaint of polyarticular joint pain and swelling of 18 months duration. This current bout of joint pain and swelling began in his shoulders and eventually involved his hands, multiple fingers, wrists, hips, and knees. He described morning stiffness lasting about one hour. Normally, this patient was physically active and enjoyed hiking but for the past 18 months his mobility was significantly limited due to the stiffness and pain. Ibuprofen provided partial, temporary relief. He had recently received steroid injections in his shoulders which provided only transient relief.

He reported an episode about 17 years prior when he had bilateral hand and foot pain along with facial redness which resolved without treatment. Then ten years ago he developed pain and swelling in his hands and other joints which were so severe that he could not dress himself. He was treated with naproxen and it gradually resolved after about 6 months.

His past medical history was notable only for seasonal allergies and a partial laminectomy for a herniated disc in 1980. There was no prior diagnosis of autoimmune disease. He denied any recent febrile illness, travel, HIV or sexually transmitted diseases, rashes, dry eyes or mouth, vision changes, headaches, respiratory symptoms, or chest pain. His only medications were over-the counter ibuprofen, MSM (methylsulfonylmethane, a popular supplement for arthritis), fish oil, vitamin D $800 \mathrm{IU}$ daily and a multivitamin. He did not smoke. He drank 2-3 glasses of wine weekly and smoked marijuana occasionally.

On exam his vital signs were within normal limits. Weight was appropriate for height. On physical exam he had mild tenderness and swelling of his right MCP (metacarpophalangeal) joint. On the left he had mild to moderate tenderness and swelling of several PIP (proximal interphalangeal) joints and the MCP joint. He was unable to make a tight fist with his left hand. Both wrists exhibited mild to moderate swelling, pain, and limitation of movement. Shoulders had mild to moderate pain and mildly limited range of motion bilaterally. He was able to move his lower extremities and had mild pain

in bilateral knees. His greater trochanters had mild tenderness bilaterally.

Laboratory data: Electrolytes, $\mathrm{CBC}$, liver function and renal function tests were within normal limits. His sedimentation rate and ANA were normal. C-reactive protein was elevated at 0.4 and Rheumatoid Factor was elevated at 18. A chest $\mathrm{X}$-ray was unremarkable.

He was given a diagnosis of rheumatoid arthritis and offered low-dose prednisone and advised to start methotrexate. The patient declined the methotrexate but took prednisone for two weeks.

Shortly after that he consumed some psilocybin mushrooms and was surprised to observe that his joint pain and swelling completely resolved for about 24 hours. In addition, his seasonal allergy symptoms also completely resolved. When he had another flare of joint pain several years later, he took four doses of psilocybin mushrooms of 2 grams each over a two-week period and again had complete resolution of his symptoms. That was one year prior to the writing of this paper. Subsequently he has been using psilocybin mushrooms periodically and he has not experienced any signs or symptoms of rheumatoid arthritis since then.

\section{Brief History of Psychedelics}

Psychedelic plants and mushrooms have been used in ritual practices and for medicinal purposes by indigenous peoples across several continents for thousands of years $[1,2]$.

When the Spanish Inquisition came to the New World in the 1600 's the use of hallucinogenic plants was viewed as

*Corresponding author: Denise S Lin, MD, Associate Professor, Departments of Psychiatry and Behavioral Science, University of New Mexico School of Medicine, Albuquerque, NM, MSC09 5030, USA, Tel: (505)-272-2333

Accepted: August 17, 2020

Published online: August 19, 2020

Citation: Lin DS (2020) Case Report: Resolution of Rheumatoid Arthritis in a Patient Consuming Psilocybin Mushrooms. J Healthcare 3(1):25-32 
a form of Devil worship and harshly punished, which drove their use deep underground [2].

In 1938 the Swiss chemistAlbert Hoffman, while working for Sandoz, was trying to develop a drug that would stimulate respiration and circulation when he synthesized lysergic acid diethylamide (LSD). He accidentally discovered its hallucinogenic properties 5 years later [3].

In the 1950's and 1960's some psychiatrists administered low doses of LSD to patients as an adjunct to psychotherapy sessions. One of the more famous proponents of LSD psychotherapy was the movie star Cary Grant $[4,5]$.

In 1957 R. Gordon Wasson, a Wall Street banker, traveled to Mexico and took psilocybin mushrooms under the guidance of a Mexican shaman named Maria Sabine. His account of the experience was published in Life Magazine [6] which served to raisepublic awareness of psychedelic substances. The 1950s and 1960's was a robust period of psychedelic research. Psychedelic agents were investigated-often with compellingly positive results, to ease the psychological and physical suffering of terminal cancer patients $[7,8]$, in people with refractory alcoholism [9,10]. A 1964 study comparing analgesic effects of LSD, meperidine, and dihydromorphinone concluded that LSD showed "a protracted and more effective action than either of the other drugs [11]." Initially, public sentiment supported the notion that psychedelic substances might possess therapeutic benefit and deserved to be investigated. However, with the growing popularity among young people to reject conventional social norms and Timothy Leary's public admonition for young people to "turn on, tune in, drop out" psychedelic substances became inextricably associated with the anti-war and anti-establishment movements. President Nixon railed against psychedelic agents and public sentiment soured. With the 1970 Controlled Substances Act psychedelic substances were placed into the Schedule 1category [12]. Some research with LSD in terminally ill patients continued until 1974, [7] but shortly thereafter all research into psychedelic substances was shut down.

\section{The Psychedelic Renaissance}

In 2011, Grob, et al. at UCLA [13] published a safety and feasibility study in the Archives of General Psychiatry on the effect of one low-moderate dose of psilocybin in a medical setting on end-of-life anxiety in patients with advanced-stage cancer. The study was placebo-controlled, and all participants received equivalent psychological preparation prior to their medication session, as well as psychotherapy support during and afterwards. The results were surprisingly robust with mood improving at 2 weeks post-dose and statistical significance at the 6-month follow up. No significant adverse events were reported [13]. Subsequently two large placebo-controlled studies at NYU and at Johns Hopkins in patients with end-of-life anxiety replicated these positive findings $[14,15]$. These studies used larger psilocybin doses and there were still no significant adverse events. In addition, the psychological benefit appeared to persist for months afterwards. For example, in the Johns Hopkins study, the overall rates of clinical response on depression and anxiety was $78 \%$ and $83 \%$, respectively at 6 months post-dose [14]. These studies indicate that psilocybin, when administered with psychological preparation and support appears to safely and significantly promote emotional breakthroughs, reduce anxiety, and improve well-being in patients facing end-of-life anxiety and depression $[14,15]$. These positive results, along with the reassuring safety profile of psilocybin have sparked aresurgence of psychedelic research. In fact, the FDA has given psilocybin research breakthrough therapy designation. Currently, active areas of research involving psilocybin or similar agents include pain [16-18], depression [14,19,20], ddictions [21,22], and inflammation [23-27].

\section{Pharmacology of Psilocybin}

Psilocybin and its active metabolite psilocin are tryptamines [28] found in more than a hundred species of mushroom, many of which belong to the Psilocybe genus. Once consumed psilocybin is largely converted to psilocin in the intestine [29], thus it is psilocin which is responsible for CNS and peripheral effects. A moderate oral dose of 12-20 $\mathrm{mg}$ psilocybin produces a state of altered perception which peaks around 80 minutes after ingestion and lasts 3-6 hours [30]. The acute psychological effects of a moderate dose include heightened sensory experiences and affect. Perceptual changes include illusions, synesthesia and altered sense of time. Recent safety studies have found minimal or no adverse effects [31]. Physical side effects appear to be limited to transient nausea, mydriasis, and modest increases in pulse and in blood pressure [31,32]. Silocybin does not produce physical dependence [32] although tolerance to the psychedelic effects may occur with frequent use [32].

\section{Toxicity of Psilocybin}

The toxicity of psilocybin is low, with a safety ratio-defined as the ratio of the lethal dose to the customary or therapeutic dose, of 1000 [33]. For comparison, the safety ratio of alcohol is 10 which is 100 times more toxic than psilocybin [33], while the toxicity of caffeine has a safety ratio of 100 , which is 10 times more toxic than that of psilocybin [34]. Using psilocybin's LD 50 of 285, (based on rodent data) a person weighing $60 \mathrm{Kg}$ would have to consume $1.7 \mathrm{~kg}$ of fresh psilocybin mushrooms to ingest a lethal dose [29].

\section{Psilocybin Mechanisms of Action}

The chemical structure of psilocybin and its active metabolite, psilocin, is very similar to that of another, well known tryptamine, the neurotransmitter serotonin. In fact, psilocybin and psilocin have high affinity at the serotonin $5 \mathrm{HT} 2 \mathrm{~A}$ receptor [35] and the intensity of the psychedelic effect is dependent upon its occupancy [35]. One of the current foci of psilocybin research is to uncover the mechanisms responsible for the persistence of the robust psychological benefits (from weeks to 6 months or more) achieved after a single dose $[14,15,19]$. Brain effects of psilocybin and other classic hallucinogens include increased neuroplasticity, and imaging studies have observed changes in network connectivity, such as enhancement of communication between regions in the brain that are normally segregated [36]. Some changes in connectivity are seen 5 weeks after a single dose [37], a 
finding which may offer clues about the persistence of their effects. The fact that many participants experience a powerful mystical experience after being administered a high dose psilocybin has been noted in all the controlled trials [13-15]. In fact, while the underlying mechanism is not yet clear, research participants who have higher scores on the MEQ (Mystical Experiences Questionnaire) are more likely to have a persistent beneficial effect [13-15].

\section{Overview of Rheumatoid Arthritis}

Rheumatoid arthritis is a chronic, inflammatory joint disease with a prevalence rate between 0.5 and $1 \%$ in developing countries [38]. It can occur at any age but the peak incidence is in the $6^{\text {th }}$ decade [39] and it is $2-3$ times more prevalent in women than in men [40].

The causes of rheumatoid arthritis are not fully understood but do seem to involve an interplay between genetic and environmental factors [41]. It is possible that single nucleotide polymorphism (SNP) genetic variations in the serotonin $5 \mathrm{HT} 2 \mathrm{~A}$ receptor could increase the risk for RA [42].

External factors such as cigarette smoking, infection or physical trauma may serve as triggers in predisposed individuals which then sets off an autoimmune response [41]. Once triggered, the immune system directs an attack on the synovial membrane in multiple joints. Endothelial activation and neovascularization occur early on followed by infiltration of the synovial membrane with immune cells, including T-cells, B-cells and monocytes [40]. Hyperplasia of the synovial lining occurs as cells such as fibroblasts and macrophages accumulate there. This activated synovium, or "pannus," then invades and damages the bone near the cartilage-bone junction [40]. Pro-inflammatory cytokines, including TNF-alpha and IL-6 are released by the immune cells within the synovial membrane. These cytokines continue to propagate an inflammatory processwhich involves TNF-alpha, NF-KB, prostaglandins and matric metalloproteases $[40,43]$ leading to pain, swelling and degradation and damage of bone and cartilage [40].

The typical clinical presentation of RA involves pain and swelling in the joints of the hands and feet and a complaint of morning stiffness. The wrists, MCP (metacarpophalangeal), MTP (metatarsal phalangeal) and PIP (proximal interphalangeal) joints are commonly involved. Larger joints, such as ankles, knees, elbows, and shoulders may also be involved [40]. Laboratory testing may include RF (Rheumatoid Factor), ACPAs (anticitrullinated peptide antibodies), erythrocyte sedimentation rate, ANA (antinuclear antibody) and C-reactive protein. Laboratory tests may be helpful but are not diagnostic and physicians must look at the entire clinical picture to make the diagnosis [40].

Guidelines for the treatment of RA emphasize an integrated approach that usually includes corticosteroids and NSAIDS [44]. However, the mainstay of treatment of RA is with a group of drugs called disease modifying antirheumatic drugs, (DMARDs) which slow the progression of joint damage $[40,44]$. There are a variety of DMARDs, including methotrexate which suppresses DNA synthesis and replication. Other drugs have been designed to antagonize inflammatory me- diators [45]. For example, the TNF Inhibitors suppress the actions of the pro-inflammatory cytokine, TNF-alpha. TNF Inhibitors are reported to lead to sustained remission in about a third of patients [44].

Without treatment, the disease leads to irreversible joint damage and significant disability [44] with $40 \%$ unable to work within 10 years of disease onset [46]. The economic burden of rheumatoid arthritis is substantial [47], with total annual healthcare costs about 3 times higher than those without a rheumatoid arthritis diagnosis [48]. In 2005 the total annual healthcare costs, (including direct and indirect costs) for rheumatoid arthritis patients overall was estimated at about $\$ 19.3$ billion [49]. While a large proportion of the cost is attributable to medication [47], costs associated with medical co-morbidity are also substantial. In the 2018 study by Chen, a group of 115,857 individuals in the Medicare system with RA was compared to a matched non-RA cohort. In this study medical co-morbidities were found to be significantly higher in those with rheumatoid arthritis diagnoses. For example, $76.4 \%$ had cardiovascular disease, compared to $44.8 \%$ without RA [48].

\section{Serotonin, TNF and Inflammation}

While serotonin is widely known as a neurotransmitter produced in the brain, the vast majority of serotonin is synthesized and stored in the intestinal mucosa $[50,51]$. Outside of the brain, serotonin has numerous important functions [52], including roles in vasoconstriction/vasodilation, hemostasis, blood pressure and other cardiac functions [52,53] as well as in the gastrointestinal system [51,52]. In addition, serotonin is involved with pain perception at both the central and peripheral nervous system levels [52].

Serotonin is also an important modulator of inflammatory processes [54-56]. Serotonin receptors and machinery for the synthesis of serotonin are found in cells of the immune system, including T-cells, macrophages, and mast cells [50]. Serotonin is involved in modulating the inflammatory response by influencing the production of TNF-alpha and some pro-inflammatory interleukins [57-60].

In most animal studies, serotonin appears to promote inflammation [25,56,61-64]. Depletion of serotonin generally leads to reductions in inflammatory responses and restoration of serotonin leads to increases in the severity of inflammatory diseases [59-62].

Given that serotonin plays an important role in inflammation it may follow that serotonergic antidepressant medications might also affect inflammatory processes. There have been a few investigations of antidepressants in inflammatory autoimmune disorders, and they do appear to provide benefit beyond their effect on mood [65-67]. For example, duloxetine was found to improve the course of irritable bowel syndrome in humans [65]. In a mouse model of multiple sclerosis, the antidepressant clomipramine ameliorated clinical signs of acute and chronic phases of the disease [66]. In a rheumatoid arthritis model in rats, paroxetine protected their joints from inflammation and destruction via inhibition of T-lymphocyte infiltration [67]. 


\section{The Serotonin $5 \mathrm{HT} 2 \mathrm{~A}$ Receptor}

Serotonin exerts its myriad effects via 7 different serotonin receptor families, all of which have subtypes (for a total of 14 different variations) [68]. The 5HT3 receptor is the only ligand-gated ion channel receptor, while all the others are G-protein-coupled receptors (GPCRs). GCPRs are proteins which span the cell-membrane. Once an agonist binds to this type of receptor a conformational change occurs in the receptor, a cascade of events follows which eventually signals specific genes to be expressed and the subsequent production of proteins which lead to biological actions $[69,70]$.

The 5 HT2A receptor subtype is a focus in psychedelic research because psychedelic agents such as psilocybin have a high affinity for this receptor, where they act as agonists [71].

In brain, the $5 \mathrm{HT} 2 \mathrm{~A}$ receptor is intimately involved with complex cognitive behaviors, such as working memory [72]. Outside the brain, $5 \mathrm{HT} 2 \mathrm{~A}$ receptors are found in a wide array of tissues and perform a variety of functions [73]. Serotonin $5 \mathrm{HT} 2 \mathrm{~A}$ receptors are also found in endothelial cells and in vascular smooth muscle [74].

Importantly, serotonin $5 \mathrm{HT} 2 \mathrm{~A}$ receptors are also found on a several differenttypes of immune cells [50], including monocytes [75], and T-lymphocytes [59] where they are involved in the mediation of immune-inflammatory processes. Thus, the $5 \mathrm{HT} 2 \mathrm{~A}$ receptor appears to be a link between serotonin, serotonin agonists, such as psilocybin, and inflammatory autoimmune disease, such as rheumatoid arthritis.

\section{Potent Anti-Inflammatory Effects of $5 \mathrm{HT} 2 \mathrm{~A}$ Receptor Agonism}

Several elegant studies [23-26,76] have greatly advanced the understanding of the immune-inflammatory functions of the $5 \mathrm{HT} 2 \mathrm{~A}$ receptor. The psychedelic agent $\mathrm{R}-\mathrm{DOI}(\mathrm{R}-2,4 \mathrm{di}-$ methoxy-4-iodoamphetamine) is a highly selective agonist at the $5 \mathrm{HT} 2 \mathrm{~A}$ receptor which makes it very useful for studying the functions of this receptor. In a study on rat aorta smooth muscle cells, and in a subsequent study with mice, activation of $5 \mathrm{HT} 2 \mathrm{~A}$ receptors by $\mathrm{R}-\mathrm{DOI}$ powerfully and potently inhibited TNF-alpha-mediated inflammatory events, including gene expression for ICAM-1, VCAM-1 and the pro-inflammatory cytokine, IL-6 $[25,76]$. In addition, this research was able to demonstrate that the anti-inflammatory effects were specific to the $5 \mathrm{HT} 2 \mathrm{~A}$ receptor, and not any other serotonin receptors [76]. Using a mouse model of asthma, mice who were pretreated with nebulized R-DOI and then exposed to a potent allergen demonstrated normal airway morphology (e.g. no evidence of asthma) while mice who were not pre-treated with the psychedelic did develop hyperresponsive airways, pulmonary inflammation, excess mucus and eosinophilia consistent with an acute asthma episode [25]. Of note, the doses of the psychedelic agent used to prevent the inflammatory response was below the threshold for behavioral effects, which, indicates thata pronounced anti-inflammatory effect may be achieved at doses below the dose that would cause hallucinogenic effects [25].

Inflammation is not only seen in acute immune reactions to allergies butis also well-established as an etiological factor in chronic diseases, such as coronary artery disease. A recent study [26] looked at the effect of selective 5HT2A receptor activation in mice who were fed a high fat, Western-type atherogenic diet, which is known to promote systemic inflammation and immune cell dysregulation eventually leading to coronary artery disease [77]. While the control group demonstrated increased expression of inflammatory markers as expected, (R)-DOI treatment prevented this inflammatory response, showing that $5-\mathrm{HT} 2$ receptor activation prevents diet-induced vascular inflammation [26].

In summary, the profound anti-inflammatory effects of the psychedelic R-DOI has been demonstrated in both acute and chronic disease models in animals. In these models, the underlying molecular mechanisms of inflammation TNF-alpha mediated, which have been demonstrated in the pathophysiology atherosclerosis, rheumatoid arthritis, psoriasis, type II diabetes, depression, schizophrenia, and Alzheimer's disease [27]. In simplistic terms, the process starts with the activation of immune cells, such as mast cells, T-lymphocytes, and monocytes. These cells contain various serotonin receptors, including the $5 \mathrm{HT} 2 \mathrm{~A}$ receptor which is known to be especially important in inflammation. Serotonin, by attaching to the $5 \mathrm{HT} 2 \mathrm{~A}$ receptor is oneway these cells can be activated. These cells then release a variety of proinflammatory cytokines, including TNF. TNF proceeds to trigger subsequent events which lead to the production of more inflammatory mediators [76]. However, when the psychedelic agent R-DOI, a high affinity agonist at the serotonin receptor binds to these cells, the proinflammatory response is suppressed [76].

\section{Functional Selectivity and the 5HT2 A Receptor}

It turns out that different agents attaching to the same receptor can elicit divergent responses in a process known as functional selectivity $[76,78,79]$. When serotonin attaches to the $5 \mathrm{HT} 2 \mathrm{~A}$ receptor specific signal transduction pathways are initiated. This process includes activation of the NF-KB Subunit $\mathrm{p} 65$ which then translocates into the cell nucleus where it causes gene expression to make proinflammatory cytokines $[76,79]$ (Also see Figure in Addendum). When a psychedelic $5 \mathrm{HT} 2 \mathrm{~A}$ agonist attaches to the receptor, the process starts the same but NF-KB Subunit $\mathrm{p} 65$ translocation into the nucleus appears to be blocked [76,79] (Also see Figure in Addendum). In simpler terms, serotonin primarily stabilizes the receptor in a conformation that recruits proinflammatory pathways, whereas psychedelics stabilize the receptor in a slightly different conformation that prevents inflammatory signaling pathways [27].

\section{Summary}

In the rheumatoid arthritis case presented here the patient declined methotrexate and serendipitously found that taking psilocybin mushrooms resolvedhis RA symptoms. At this writing he has been symptom free for over one year. He continues to take moderate doses of psilocybin mushrooms approximately once a month. RA is a progressive inflammatory, autoimmune disease which is likely caused by interactions between an environmental trigger and a genetic pre- 


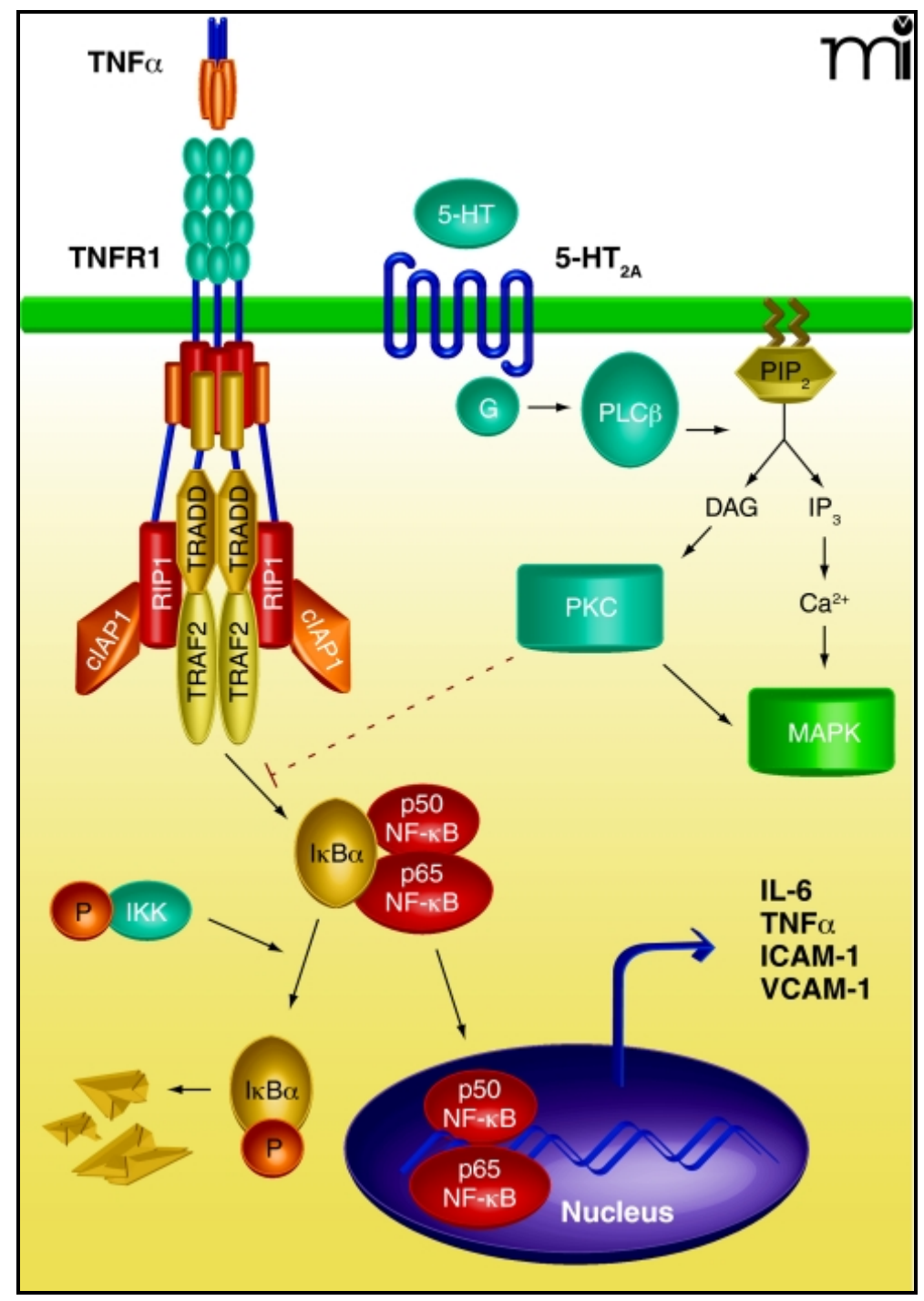

A proposed mechanism by Pelletier and Seigel [79] of crosstalk between the TNF-1 receptor and the 5HT2A receptor. Once TNF-alpha binds to the receptor complex, IKB kinase is activated to degrade IKB into its NF- $\mathrm{B}$ B subunits. NF- $\mathrm{KB}$ enters the nucleus where they act as transcription factors to produce more TNF and additional pro-inflammatory cytokines.

The $5 \mathrm{HT} 2 \mathrm{~A}$ receptor is a G-coupled protein receptor (GCPR), thus when an agonist, such as serotonin binds to it, the enzyme PLC is freed to catalyze the breakdown of PIP2, thereby producing IP3 and DAG. IP3 mobilizes CA $^{2+}$ which induces multiple responses, including activation of MAPK. DAG goes on to activate PKC. According to Yu, et al. [76] anti-inflammatory effects take place via PKC activation.

TNF1: Tumor Necrosis Factor 1; TRADD: Adapter Protein; TRAF2: Ringfinger-Containing Protein; clAP1: Inhibitor of Apoptosis; RIP1: Protein Kinase; ІкB: Inhibitor of Kappa Beta; NF-кB: Nuclear Factor Kappa Beta; PLC: Protein Kinase C; PIP2: Inositol Lipid Phosphatidylinositol Bisphosphate; IP3: Inositol Triphosphate; DAG: Diacylglycerol; MAPK: Mitogen-Activated Protein Kinase; IL-6: Interleukin-6; ICAM1: Intercellular Adhesion Molecule1; VCAM1: Vascular Cell Adhesion Molecule1.

disposition (possibly a SNP in the gene coding for the $5 \mathrm{HT} 2 \mathrm{~A}$ receptor). The pathophysiology of RA includes activation of immune cells which produces a cascade of TNF-alpha-mediated events. TNF is the target of a class of disease-modifying drugs developed to slow the disease course of RA, and which appear to do so in about $1 / 3$ of patients [44]. Immune cells involved in the inflammatory process have been found to contain serotonin $5 \mathrm{HT} 2 \mathrm{~A}$ receptors, which when bound to serotonin appear to promote TNF-induced inflammation, yet when bound to a psychedelic agonist, such as R-DOI strongly inhibit TNF-induced inflammation. While psilocybin itself has not yet been investigated as a modifier of inflammation, it is plausible that it could behave like R-DOI in suppressing in- flammation because it too is a high-affinity, psychedelic agonist at the serotonin $5 \mathrm{HT} 2 \mathrm{~A}$ receptor. If this is the case it could explain why this patient's RA has remained in remission despite not taking a DMARD.

\section{Discussion}

There are many limitations inherent in a single case report and many questions remain unanswered. For one, there is no way to be sure if the patient experienced relief due to the anti-inflammatory effect of psilocybin's 5HT2 agonism, the placebo effect, or because his emotional state was enhanced by the mood altering effect of the mushrooms. 
Assuming the former, then next question might be: To what extent is the "psychedelic" nature of psilocybin relevant to the anti-inflammatory effects? Certainly in the psychiatric research, those participants who met criteria for having had a mystical experience had a greater chance of having resolution or significant improvement of depression or anxiety [13-15]. If it turns out that all therapeutic effects of psychedelic agents depend upon experiencing such a "non-ordinary" state of consciousness it would ultimately limit the use of these agents to those people who have been carefully screened and determined to be psychologically resilient and without a history of psychosis.

Evidence so far, however, suggests that a mystical or hallucinatory experience may not be necessary to achieve a clinically relevant anti-inflammatory effect. As noted previously, rodent experiments with the highly selective $5 \mathrm{HT} 2 \mathrm{~A}$ receptor agonist DOI demonstrate potent anti-inflammatory actions at doses below the threshold for perceptual effects. Further, a Mclean Hospital survey of cluster headache suffers found that $42 \%$ of participants who self-treated their cluster headaches with LSD or psilocybin reported complete or partial relief at doses that were sub-hallucinogenic [80]. While the mechanism of action of psychedelic agents in cluster headaches is unknown (and unverified) this survey does at least hint that clinically significant beneficial effects might occur at doses that are too low to produce psychological effects.

A third, unanswered question relates to the fact that psilocybin appears to bind to several other serotonin receptor subtypes besides 5HT2A, including 1D, 2B, 2C, 5, 6 and 7 [81]. If so, could the anti-inflammatory effects be attributable to a receptor or receptors which do not cause psychological effects? The functions of all the serotonin receptor subtypes have not been fully elucidated. However, anti-inflammatory effects in the cerebral vasculature are seen with activation of $5 \mathrm{HT} 1 \mathrm{~B}$ and 5HT1D receptors as exemplified by the migraine drug sumatriptan [82]. It is then conceivable that psilocybin or psilocin binding at the $5 \mathrm{HT} 1 \mathrm{D}$ receptor could contribute to some of the anti-inflammatory effect, but the contribution would likely be very small as experiments with the highly selective $2 \mathrm{~A}$ receptor agonist $\mathrm{DO}$ elicit a dramatic anti-inflammatory response without any involvement of the 5HT1D receptor.

Finally, how important is it that this patient was consuming whole mushrooms, not pure psilocybin? Mushrooms contain a large variety of nutrients and other molecules which may inhibit TNF-alpha, inflammatory interleukins, prostaglandins or act as free-radical scavengers [83]. Therefore, it is possible that some of those components could be contributing to his disease remission. Edible mushroom constituents with anti-inflammatory properties include saccharides, fatty acids, phenols, indoles, antioxidant vitamins, terpenoids, glutathione and minerals [83]. For example, lycopene, a common mushroom constituent has been found toinhibits NF-KB signaling [84]. Research on edible mushrooms has demonstrated a variety of anti-inflammatory actions $[85,86]$.

While many more questions are yet to be explored the fact remains that rheumatoid arthritis is associated with significant human suffering, disability and a heavy economic burden. There is a need for additional cost-effective and safe treatments. Growing evidence indicates that psilocybin mushrooms modulate the immune-inflammatory process in a beneficial manner and do so after only a single dose. Given its anti-inflammatory effects, along with the reassuring safety profile and low toxicity the therapeutic potential of psilocybin mushrooms in inflammatory diseases warrants further study.

\section{Authors Declaration}

Case Presentation (Information obtained from medical records, dated $3 / 3 / 2014$ and $3 / 14 / 2014$ as well as a patient interview).

\section{References}

1. Samorini G (1992) The oldest representations of hallucinogenic mushrooms in the world.

2. McKenna TK (1993) Food of the gods : The search for the original tree of knowledge. A radical history of plants, Drugs, and Human evolution. Bantam books 331.

3. Hofman A (1980) LSD - My problem child. McGraw-Hill.

4. Hofman A (1980) LSD - my problem child.

5. Gehman R (1960) Ageless Cary Grant. Good Housekeep.

6. Grant C (1963) Archie Leach. Ladies Home J.

7. Grof S, Goodman LE, Richards WA, et al. (1973) LSD assisted psychotherapy in patients with terminal cancer. Int Pharmacopsychiatry 8: 129-144.

8. Pahnke WN, Kurland AA, Goodman, et al. (1969) LSD-assisted psychotherapy with terminal cancer patients. Curr Psychiatr Ther 9: 144-152.

9. Smart RG, Storm T (1964) The efficacy of LSD in the treatment of alcoholism. Q J Stud Alcohol 25: 333-338.

10. Smith CM (1964) Exploratory and controlled studies of lysergide in the treatment of alcoholism. Q J Stud Alcohol 25: 742-747.

11. Kast EC, CV (1964) Study of lysergic acid diethylamide as an analgesic agent. Anesth Analg 43: 285-291.

12. Gabay M (2013) The federal controlled substances act: Schedules and pharmacy registration. Hosp Pharm 48: 473-474.

13. Grob CS, Danforth AL, Chopra GS, et al. (2011) Pilot study of psilocybin treatment for anxiety in patients with advanced-stage cancer. Arch Gen Psychiatry 68: 71-78.

14. Griffiths RR, Johnson MW, Carducci MA, et al. (2016) Psilocybin produces substantial and sustained decreases in depression and anxiety in patients with life-threatening cancer: A randomized double-blind trial. J Psychopharmacol 30: 1181-1197.

15. Ross S, Bossis A, Guss J, et al. (2016) Rapid and sustained symptom reduction following psilocybin treatment for anxiety and depression in patients with life-threatening cancer: A randomized controlled trial. J Psychopharmacol 30: 1165-1180.

16. Tabor A, Keogh E, Eccleston C (2017) Embodied pain - Negotiating the boundaries of possible action. Pain 158: 1007-1011.

17. Whelan A, Johnson MI (2018) Lysergic acid diethylamide and psilocybin for the management of patients with persistent pain: $A$ potential role? Pain Manag 8: 217-229.

18. Ramachandran V, Chunharas C, Marcus Z, et al. (2018) Relief 
from intractable phantom pain by combining psilocybin and mirror visual-feedback (MVF). Neurocase 24: 105-110.

19. Carhart Harris RL, Bolstridge M, Day CMJ, et al. (2018) Psilocybin with psychological support for treatment-resistant depression: Six-month follow-up. Psychopharmacology (Berl) 235: 399-408.

20. Roseman L, Nutt DJ, Carhart Harris RL (2018) Quality of acute psychedelic experience predicts therapeutic efficacy of psilocybin for treatment-resistant depression. Front Pharmacol 8: 974.

21. Bogenschutz MP, Forcehimes AA, Pommy JA, et al. (2015) Psilocybin-assisted treatment for alcohol dependence: A proof-ofconcept study. J Psychopharmacol 29: 289-299.

22. Johnson MW, Garcia Romeu A, Griffiths RR (2017) Long-term follow-up of psilocybin-facilitated smoking cessation. Am J Drug Alcohol Abuse 43: 55-60.

23. Nau F, Miller J, Saravia J, et al. (2015) Serotonin 5-HT2 receptor activation prevents allergic asthma in a mouse model. Am J Physiol Lung Cell Mol Physiol 308: L191-L198.

24. Nau F, Yu B, Martin D, et al. (2013) Serotonin 5-HT2A receptor activation blocks TNF- $\alpha$ mediated inflammation Invivo. PLoS One 8: e75426.

25. Flanagan TW, Sebastian MN, Battaglia DM, et al. (2019) 5-HT2 receptor activation alleviates airway inflammation and structural remodeling in a chronic mouse asthma model. Life Sci 236: 116790.

26. Flanagan TWT, Sebastian MNM, Battaglia DDM, et al. (2019) Activation of 5-HT2 receptors reduces inflammation in vascular tissue and cholesterol levels in high-fat diet-fed apolipoprotein e knockout mice. Sci Sep 9: 13444.

27. Flanagan TW, Nichols CD (2018) Psychedelics as anti-inflammatory agents. Int Rev Psychiatry 30: 363-375.

28. Presti DE (2016) Foundational concepts in neuroscience: A brainmind odyssey. J Undergrad Neurosci Educ 14: 298.

29. Dinis Oliveira RJ (2017) Metabolism of psilocybin and psilocin: Clinical and forensic toxicological relevance. Drug Metab Rev 49: 84-91.

30. Passie T, Seifert J, Schneider U, et al. (2002) The pharmacology of psilocybin. Addict Biol 7: 357-364.

31. Hasler F, Grimberg U, Benz MA, et al. (2004) Acute psychological and physiological affects of psilocybin in healthy humans: A double-blind, placebo-controlled dose-effect study. Psychopharmacology (Berl) 172: 145-156.

32. Johnson MW, Richards WA, Griffiths RR (2008) Human hallucinogen research: Guidelines for safety. J Psychopharmacol 22 603-620.

33. Gable RS (2004) Comparison of acute lethal toxicity of commonly abused psychoactive substances. Addiction 99: 686-696.

34. Gable RS (1993) Toward a comparative overview of dependence potential and acute toxicity of psychoactive substances used nonmedically. Am J Drug Alcohol Abuse 19: 263-281.

35. Madsen MK, Fisher PM, Burmester D, et al. (2019) Psychedelic effects of psilocybin correlate with serotonin $2 \mathrm{~A}$ receptor occupancy and plasma psilocin levels. Neuropsychopharmacology 44: 1328-1334.

36. Mertens LJ, Wall MB, Roseman L, et al. (2020) Therapeutic mechanisms of psilocybin: Changes in amygdala and prefrontal functional connectivity during emotional processing after psilo- cybin for treatment-resistant depression. J Psychopharmacol 34: 167-180.

37. Carhart Harris RL, Roseman L, Bolstridge M, et al. (2017) Psilocybin for treatment-resistant depression: FMRI-measured brain mechanisms. Sci Rep 7: 13187.

38. Smolen JS, Aletaha D, McInnes IB (2016) Rheumatoid arthritis. Lancet 388: 2023-2038.

39. Myasoedova E, Crowson CS, Kremers HM, et al. (2010) Is the incidence of rheumatoid arthritis rising?: Results from olmsted county, minnesota, 1955-2007. Arthritis Rheum 62: 1576-1582.

40. Aletaha D, Smolen JS (2018) Diagnosis and management of rheumatoid arthritis: A review. JAMA - J Am Med Assoc 320: 13601372.

41. Viatte S, Barton A (2017) Genetics of rheumatoid arthritis susceptibility, severity, and treatment response. Semin Immunopathol 39: 395-408.

42. Kling A, Seddighzadeh $M$, Ärlestig L, et al. (2008) Genetic variations in the serotonin 5-HT2A receptor gene (HTR2A) are associated with rheumatoid arthritis. Ann Rheum Dis 67: 1111-1115.

43. Ridgley LA, Anderson AE, Pratt AG (2018) What are the dominant cytokines in early rheumatoid arthritis? Curr Opin Rheumatol 30: 207-214.

44. Wolfe $F$ (1996) The natural history of rheumatoid arthritis. J Rheumatol 44: 13-22.

45. Smith HR (2020) Rheumatoid arthritis (RA): Practice essentials, background, pathophysiology.

46. Sokka T, Kautiainen H, Möttönen T, et al. (1999) Work disability in rheumatoid arthritis 10 years after the diagnosis. J Rheumatol 26: 1681-1685.

47. Hsieh PH, Wu O, Geue C, et al. (2020) Economic burden of rheumatoid arthritis: A systematic review of literature in biologic era. Ann Rheum Dis 79: 771-777.

48. Chen $\mathrm{Cl}$, Wang L, Wei W, et al. (2018) Burden of rheumatoid arthritis among US medicare population: Co-morbidities, healthcare resource utilization and costs. Rheumatol Adv Pract 2: i1-i9.

49. Birnbaum H, Pike C, Kaufman R, et al. (2010) Societal cost of rheumatoid arthritis patients in the US. Curr Med Res Opin 26: 77-90.

50. Wu H, Denna TH, Storkersen JN, et al. (2019) Beyond a neurotransmitter: The role of serotonin in inflammation and immunity. Pharmacol Res 140: 100-114.

51. Kim DY, Camilleri M (2000) Serotonin: A mediator of the braingut connection. Am J Gastroenterol 95: 2698-2709.

52. Berger M, Gray JA, Roth BL (2009) The Expanded Biology of Serotonin. Annu Rev Med 60: 355-366.

53. Watts SW, Davis RP (2011) 5-Hydroxtryptamine receptors in systemic hypertension: An arterial focus. cardiovasc ther 29: 54-67.

54. Cirillo C, Vanden Berghe P, Tack J (2011) Role of serotonin in gastrointestinal physiology and pathology. Minerva Endocrinol 36: 311-324.

55. Aidy S El, Dinan TG, Cryan JF (2014) Immune modulation of the brain-gut-microbe axis. Front Microbiol 5: 146.

56. Ghia J, Li N, Wang H, et al. (2009) Serotonin has a key role in pathogenesis of experimental colitis. Gastroenterology 137: 1649-1660. 
57. Dürk T, Panther E, Müller T, et al. (2005) 5-Hydroxytryptamine modulates cytokine and chemokine production in LPS-primed human monocytes via stimulation of different 5-HTR subtypes. Int Immunol 17: 599-606.

58. Shajib MS, Khan WI (2015) The role of serotonin and its receptors in activation of immune responses and inflammation. Acta Physiol 213: 561-574.

59. Herr N, Bode C, Duerschmied D (2017) The effects of serotonin in immune cells. Front Cardiovasc Med 4: 48.

60. Kubera M, Maes M, Kenis G, et al. (2005) Effects of serotonin and serotonergic agonists and antagonists on the production of tumor necrosis factor $\alpha$ and interleukin-6. Psychiatry Res 134: 251-258.

61. Harbuz MS, Marti O, Lightman SL, et al. (1998) Alteration of central serotonin modifies onset and severity of adjuvant-induced arthritis in the rat. Br J Rheumatol 37: 1077-1083.

62. Chabbi Achengli Y, Coman T, Collet C, et al. (2016) Serotonin is involved in autoimmune arthritis through th17 immunity and bone resorption. Am J Pathol 186: 927-937.

63. Margolis KG, Stevanovic K, Li Z, et al. (2014) Pharmacological reduction of mucosal but not neuronal serotonin opposes inflammation in mouse intestine. Gut 63: 928-937.

64. Nishiyama T (2009) Acute effects of sarpogrelate, a 5-HT2A receptor antagonist on cytokine production in endotoxin shock model of rats. Eur J Pharmacol 614: 122-127.

65. Brennan BP, Fogarty K V, Roberts JL, et al. (2009) Duloxetine in the treatment of irritable bowel syndrome: An open-label pilot study. Hum Psychopharmacol 24: 423-428.

66. Faissner S, Mishra M, Kaushik DK, et al. (2017) Systematic screening of generic drugs for progressive multiple sclerosis identifies clomipramine as a promising therapeutic. Nat Commun 8: 1990.

67. Wang $Q$, Wang L, Wu L, et al. (2017) Paroxetine alleviates T lymphocyte activation and infiltration to joints of collagen-induced arthritis. Sci Rep 7: 45364

68. Nichols DE, Nichols CD (2008) Serotonin receptors. Chem Rev 108: 1614-1641.

69. Raymond JR, Mukhin YV, Gelasco A, et al. (2001) Multiplicity of mechanisms of serotonin receptor signal transduction. Pharmacol Ther 92: 179-212.

70. Grotewiel MS, Sanders Bush E (1999) Differences in agonist-independent activity of $5-\mathrm{HT}(2 \mathrm{~A})$ and $5-\mathrm{HT}(2 \mathrm{C})$ receptors revealed by heterologous expression. Naunyn Schmiedebergs Arch Pharmacol 359: 21-27.

71. Niven JE (2017) Foundational concepts in neuroscience: A brainmind odyssey. Q Rev Biol 92: 328-328.

72. Williams GV, Rao SG, Goldman Rakic PS (2002) The physiological role of 5-HT 2A receptors in working memory. J Neurosci 22: 2843-2854.
73. Nichols DE, Johnson MW, Nichols CD (2017) Psychedelics as medicines: An emerging new paradigm. Clin Pharmacol Ther 101: 209-219.

74. Nagatomo T, Rashid M, Abul Muntasir H, et al. (2004) Functions of 5-HT 2A receptor and its antagonists in the cardiovascular system. Pharmacol Ther 104: 59-81.

75. Cloëz Tayarani I, Petit-Bertron AF, Venters HD, et al. (2003) Differential effect of serotonin on cytokine production in lipopolysaccharide-stimulated human peripheral blood mononuclear cells: Involvement of 5-hydroxytryptamine2A receptors. Int Immunol 15: 233-240.

76. Yu B, Becnel J, Zerfaoui M, et al. (1997) Serotonin 5-hydroxytryptamine $2 \mathrm{~A}$ receptor activation suppresses tumor necrosis factor-induced inflammation with extraordinary potency. J Pharmacol Exp Ther 327: 316-323.

77. Manzel A, Muller DN, Hafler DA, et al. (2014) Role of "western diet" in inflammatory autoimmune diseases. Curr Allergy Asthma Rep 14: 404.

78. Urban JD, Clarke WP, Von Zastrow M, et al. (2007) Functional selectivity and classical concepts of quantitative pharmacology. J Pharmacol Exp Ther 320: 1-13.

79. Pelletier M, Siegel RM (2009) Wishing away inflammation? New links between serotonin and TNF signaling. Mol Interv 9: 299301.

80. Sewell RA, Halpern JH, Pope HG (2006) Response of cluster headache to psilocybin and LSD. Neurology 66: 1920-1922.

81. Halberstadt AL, Geyer MA (2011) Multiple receptors contribute to the behavioral effects of indoleamine hallucinogens. Neuropharmacology 61: 364-381.

82. Pierce PA, Xie GX, Peroutka SJ, et al. (1996) Dual effect of the serotonin agonist, sumatriptan, on peripheral neurogenic inflammation. Reg Anest 21: 219-225.

83. Muszyńska B, Grzywacz Kisielewska A, Kała K, et al. (2018) Anti-inflammatory properties of edible mushrooms: A review. Food Chem 243: 373-381.

84. Jeong Y, Lim JW, Kim H (2019) Lycopene inhibits reactive oxygen species-mediated nf-kb signaling and induces apoptosis in pancreatic cancer cells. Nutrients 11: 762.

85. Benson KF, Stamets P, Davis R, et al. (2019) The mycelium of the trametes versicolor (Turkey tail) mushroom and its fermented substrate each show potent and complementary immune activating properties in vitro. BMC Complement Altern Med 19: 342.

86. Drori A, Shabat $Y$, Ben Ya'Acov A, et al. (2016) Extracts from lentinula edodes (Shiitake) edible mushrooms enriched with vitamin D exert an anti-inflammatory hepatoprotective effect. J Med Food 19: 383-389.

DOI: $10.36959 / 569 / 456$

Copyright: (C) 2020 Lin DS. This is an open-access article distributed under the terms of the Creative Commons Attribution License, which permits unrestricted use, distribution, and reproduction in any medium, provided the original author and source are credited. 